\title{
Structure and Its Reliability and Validity of Employees' Trust in Organizational Safety
}

\author{
Su-Xia Liu ${ }^{1}$, Ying Zhou ${ }^{1}$, Yao Cheng ${ }^{1} \&$ Gilbert Joshua Atteh Sewu ${ }^{1}$ \\ ${ }^{1}$ School of management, Jiangsu University, China \\ Correspondence: Suxia Liu, School of management, Jiangsu University, No. 301 Xuefu Road, Jingkou District, \\ Zhenjiang, Jiangsu, China. E-mail: 16449926@qq.com
}

Received: March 4, 2019

doi:10.5539/ijbm.v14n5p115
Accepted: April 6, 2019

Online Published: April 18, 2019

URL: https://doi.org/10.5539/ijbm.v14n5p115

\begin{abstract}
Employees' trust in organizational safety is conducive in enhancing employees' safety participation behavior from a psychological perspective. This study conceptualized employees' trust in organizational safety and divided it into 3 dimensions by reviewing the previous literature. Questionnaires were designed based on the reference and revision of relevant scales in previous studies. Data was collected from 716 frontline employees to confirm the reliability and validity of the structure of employees' trust in organizational safety. The result indicated that employees' trust in organizational safety can be divided into three aspects and the scale with 16 -items is valid and reliable.
\end{abstract}

Keywords: employees' trust in organizational safety, employees' safety participation behavior, structural equation model, reliability and validity, safety

\section{Introduction}

Any time an accident happens or occurs, organizations investigate the cause of those accident with an intention of knowing the reasons why the accident occurred. This is because, organizations want to make sure no accidents occur again through similar causes. It is a known truth that, the incidence of safety accident is an important part of the organization's safety performance which is an indispensable section of organizational performance.

In the past few years, trust has become an important factor in the welfare and performance of the organization (Carmen Alexandra Ranca, Eugen Iordanesc, 2013). Trust, thus, can be viewed as an element of organizational safety performance. Many scholars suggested that trust has a promotive effect on open communication (Lisa M. Kath, Karen M. Marks, Joyce Ranney, 2010, Stacey M. Conchie, Calvin Burns, 2008), which could result in the decrease in safety incidents. Employees' trust in their organizations can promote themselves to expand their work content voluntarily (Podsakoff, MacKenzie, Moorman, \& Fetter, 1990). It has been found by Conchie and Donald (2009) that trust may play a moderating role in the relationship between safety-specific transformational leadership and employee safety citizenship behaviors.

Almost all employers are eager to build their employees' trust in the organization (Zhang, Tsui, \& Song, et al., 2008). However, although trust has been increasingly showed as a variable of safety, only a few studies focus on the nature of trust (Stacey M. Conchie, Ian J. Donald, Paul J. Taylor, 2006) and there is no systematic research on the employees' trust in organizations, let alone in the field of safety production. The present study, thus, aims to conceptualize employees' trust in organization from the perspective of safety production and to divide the dimensions of employees' trust in organizational safety scientifically.

\section{Literature Review}

Trust, an indicator of the quality of social exchange (Gil Luria, 2010), which can bring together people from different backgrounds (Mayer et al., 1995). Trust can be identified as an intention of relying on a person based on his safety behavior or his will of working safely (Denise M. Rousseau et al., 1998, Gil Luria, 2010, Stacey M. Conchie et al., 2009, Stacey M. Conchie et al., 2006). Trust functions as a central part of safety climate, but is seldom measured by academic research (Calvin Burns, Kathryn Mearns \& Peter McGeorge, 2006). The lack of trust will be detrimental to the exchange of information, weaken the effectiveness of a common solution to each other, and may reduce the ability of all parties to resolve their differences (Stoel \& Muhanna, 2012).

Organizational trust is the extent to which employees are willing to be affected by organizational behavior 
(Lewicki, McAllister, \& Bies, 1998 $\mathrm{Ng}$, 2015). Organizational trust plays an essential role in implementing safety organizational systems (Eugen Avram et al., 2015) and improving organizational safety outcomes. Organizational trust also mediates the relationship between safety climate and organizational outcomes (Lisa M. Kath, 2010). Organizational trust is one of the most significant result of organizational justice (Shabnam Bidarian, 2012). Organizational trust has a positive impact on employees' safety behavior (Eugen Avram et al., 2015).

Based on the previous literature above, this study defines Employees' Trust in Organizational Safety(ETOS) as the employees' belief, confidence and support attitude toward all the organization's safety activities, such as safety policies, safety management activities, safety facilities, etc. With a positive expectation that the organization will do as much as possible to avoid the occurrence of safety accidents and protect the health and safety of employees' life and property, employees who have a trust in organizational safety will spontaneously be willing to expose their weaknesses, their own safety operation mistakes and the potential safety risks around themselves to the organization.

Trust is considered as emotional and cognitive dimension (Lewis \& Weigert, 1985). Jones and George (1998) divided trust into conditional trust and unconditional trust. Trust also can be divided into three dimensions: good faith, integrity and ability (Rämö, 2004). Chathoth et al. (2011) thought that organizational trust consisted of three aspects: integrity, commitment and dependability. When employees trust their perceived safety climate, which refers to personal perceptions of safety policies, safety procedures and safety practices in workplace, is positive, they might reciprocate and benefit the organization by taking safety participation behaviors (Andrew Neal, \& Mark Griffin, 2006). Moreover, it is recognized fact that the unsafe state of the equipment is one of the causes of safety accidents. The current study therefore divides Employees' Trust in Organizational Safety into three dimensions: (1) Employees' trust in organizational safety institution (ETSI). Whitener (2001) showed that when employees perceived that they are supported and committed by their organization, their organizational trust and commitment will be stronger. After the organization has formulated policies to protect the health and safety of its employees, employees have an organizational commitment to the organization (Amponsah-Tawiah \& Mensah, 2016). (2) Employees' trust in organizational safety management practice(ETSM). Trusting the organizations and supervisors can increase employees' intention of safety participation (Stacey M. Conchie,2009) by encouraging employees to report their unsafe behaviors, unreasonable circumstances in the safety policies and procedures and potential hazards in the workplace Into their supervisors and organizations (Eugen Avram et al., 2015). The new employees' safety expectations are related to the level of safety-specific trust among their supervisors (Christopher Burt, 2012). (3) Employees' trust in organizational safety equipment(ETSE). Eugen Avram et al. (2015) states that workspace safety has an important direct relationship with organizational trust.

\section{Method}

\subsection{Participants}

The questionnaires were distributed to several organizations from 6 industries in China, including construction industry, manufacturing industry, new energy industry, no-coal mine and among other organizations. After eliminating the invalid questionnaires, the number of the actual effective questionnaires was 716 .

\subsection{Scale Development}

Employees' trust in organizational safety institution was assessed by using a combined, revised and updated version of Arlene Walker's (2010) employer safety obligations scale and Mullen's (2017) perceived employer safety obligation measure. This scale consisted of 5 items, such as "Organization has visible safety documentation.", "Organization implements safety policies and practices." etc. A 5-point Likert-type scale ranging from 1 (strongly disagree) to 5 (strongly agree) was used to measure the employees' in organizational safety institution.

Employees' trust in organizational safety management practices was also measured by using a screening and integrated version of Arlene Walker's (2010) employer safety obligations scale and Mullen's (2017) perceived employer safety obligation measure. This scale consisted of 7 items, such as "Organization provides me with safety training.", "Organization shows how to deal with emergencies." etc. A 5-point Likert-type scale ranging from 1 (strongly disagree) to 5(strongly agree) was used to measure the employees' trust in organizational safety management.

Employees' trust in organizational safety equipment was also measured by using a scale with 4 items chosen from Arlene Walker's (2010) employer safety obligations scale and Jane Mullen (2017) et al., perceived employer safety obligation measure, such as "Organization provides me with personal protective equipment.", 
"Organization ensures the equipment is maintained and properly functioning." etc. A 5-point Likert-type scale ranging from 1(strongly disagree) to 5(strongly agree) was used to measure the employees' trust in organizational safety equipment.

Before the formal research, we conducted a simple test and a preliminary test on the developed scale. The results showed that the scale developed in this study can be used for formal research. The final questionnaire includes the 16 items and demographic questions. All items are listed in Table 1.

Table 1. Dimensions and items of employees' trust in organizational safety

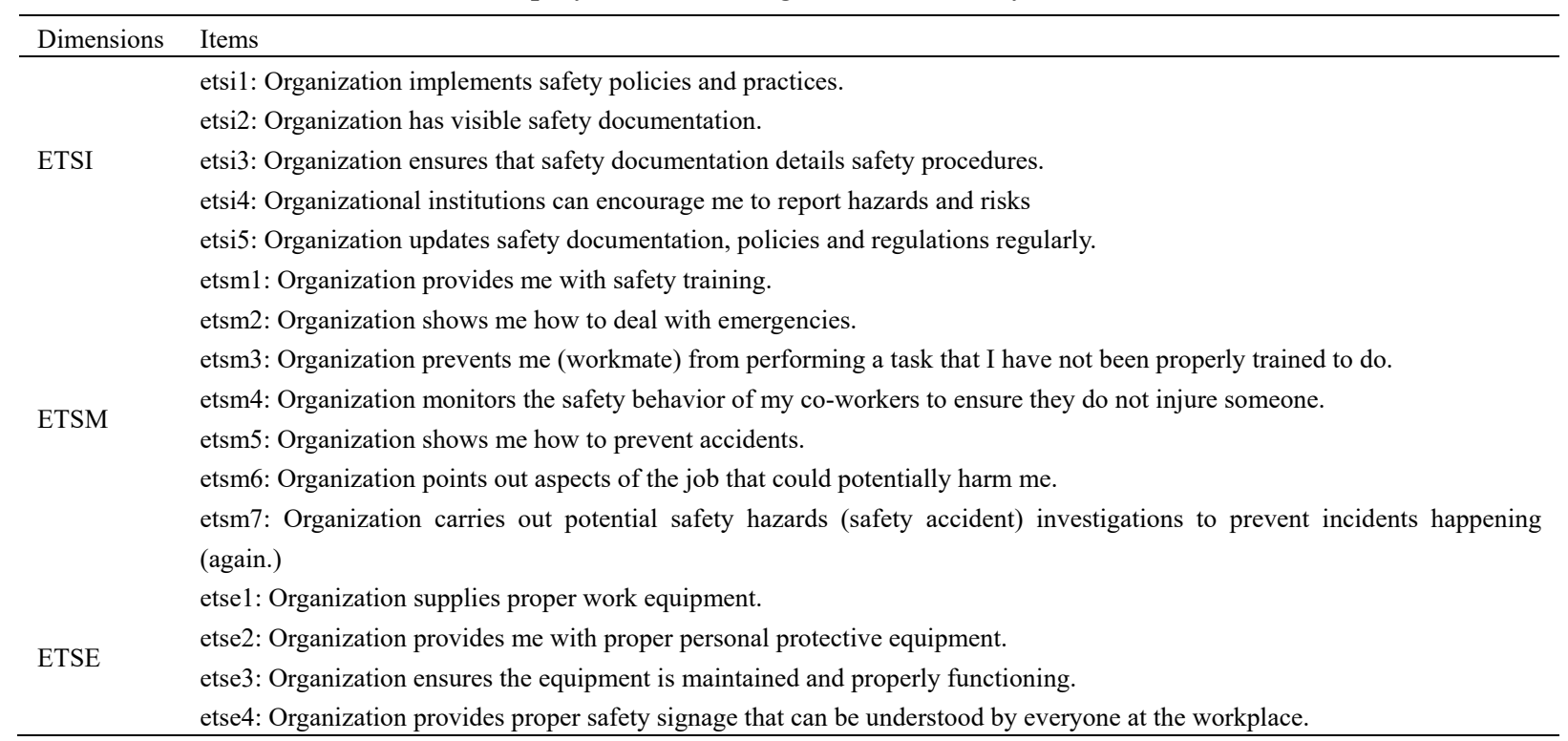

\subsection{Data Analysis}

Data used in this study were randomly divided into two parts by excel 2016 software. One part of them is used for exploratory factor analysis tests by using SPSS 19.00 statistical software and the other is used for confirmatory factor analysis tests using LISREL8.7 software.

\section{Results}

\subsection{Study Sample Size}

In general, the sample size needs to be 10-15 times of the number of items. The 16 items require a study sample size of 240 . The sample size of this study is 716 which has met the statistical requirement. Table 2 shows the demographic information of study sample. 
Table 2. Demographics of study sample

\begin{tabular}{|c|c|c|c|}
\hline Variables & & Numbers & Percentage \% \\
\hline \multirow[t]{2}{*}{ Gender } & Male & 507 & 70.81 \\
\hline & Female & 209 & 29.19 \\
\hline \multirow{4}{*}{$\begin{array}{l}\text { Age } \\
\text { (years old) }\end{array}$} & $\sim 25$ & 164 & 22.90 \\
\hline & $26 \sim 35$ & 301 & 42.04 \\
\hline & $36 \sim 45$ & 193 & 26.96 \\
\hline & $46 \sim$ & 58 & 8.10 \\
\hline \multirow{4}{*}{$\begin{array}{l}\text { Years of } \\
\text { work experience } \\
\text { (years) }\end{array}$} & $\sim 5$ & 447 & 62.43 \\
\hline & $6 \sim 15$ & 203 & 28.35 \\
\hline & $16 \sim 25$ & 55 & 7.68 \\
\hline & $25 \sim$ & 11 & 1.54 \\
\hline \multirow{4}{*}{$\begin{array}{l}\text { Accident experienced } \\
\text { (Multiple choices) }\end{array}$} & Minor injury accident & 108 & 15.08 \\
\hline & Major injury accident & 12 & 1.68 \\
\hline & Occupational disease & 72 & 10.06 \\
\hline & No accident & 540 & 75.42 \\
\hline \multirow{5}{*}{$\begin{array}{l}\text { Degree } \\
\text { of education }\end{array}$} & Primary school and below & 6 & 0.84 \\
\hline & Junior high school & 252 & 35.20 \\
\hline & High school & 273 & 38.13 \\
\hline & Undergraduate or junior college & 169 & 23.60 \\
\hline & Postgraduate and above & 16 & 2.23 \\
\hline \multirow[t]{9}{*}{ Organizations } & Hazardous chemicals & 26 & 3.63 \\
\hline & Construction industry & 58 & 8.10 \\
\hline & Non-coal mine & 53 & 7.40 \\
\hline & Building material industry & 51 & 7.12 \\
\hline & Electronic component industry & 27 & 3.77 \\
\hline & New energy industry & 90 & 12.57 \\
\hline & Photovoltaic industry & 287 & 40.08 \\
\hline & Manufacturing industry & 53 & 7.40 \\
\hline & Power construction industry & 71 & 9.93 \\
\hline
\end{tabular}

\subsection{Reliability}

Cronbach's $\alpha$ coefficient is currently widely used to measure the reliability of the scale. It is generally considered that the coefficient is greater than 0.7 indicating that the internal consistency is acceptable. Table 3 shows the reliability analysis.

Table 3. Results of reliability analysis

\begin{tabular}{llll}
\hline Dimensions & Number of Items & Cronbach's $\alpha$ & Total Cronbach's $\alpha$ \\
\hline ETSI & 5 & 0.891 & \\
ETSM & 7 & 0.915 & 0.945 \\
ETSE & 4 & 0.847 & \\
\hline
\end{tabular}

Generally believed that if the value of Cronbach's $\alpha$ is greater than 0.7 , it represents the reliability of the scale can be accepted and if the value of Cronbach's $\alpha$ is greater than 0.8 , it indicates that the scale has good reliability. The results of reliability analysis showed that the scale had a good reliability.

\subsection{Factor Analysis}

The scale developed in this study is formed by drawing on the relevant literature and theoretical analysis, so it has a good content validity.

\subsubsection{Exploratory Factor Analysis}

The value of KMO Measure of Sampling Adequacy was 0.943 and Bartlett's Test of Sphericity was significant $\left(\chi^{2}=3842.554, \mathrm{P}<0.000\right)$. Both of these indicated that the data was appropriate for factor analysis.

The principal component analysis was conducted among all the 16 items. The result showed that the 3 
dimensions were extracted and account for $68.72 \%$ variance. The result of principal component analysis is shown in Table 4.

Table 4. Result of Principal component analysis

\begin{tabular}{|c|c|c|c|c|}
\hline \multicolumn{5}{|c|}{ Rotated Component Matrix } \\
\hline Dimension Code & Item Code & 1 & 2 & 3 \\
\hline \multirow{5}{*}{ ETSI } & a1 & 0.312 & $0.774 *$ & 0.188 \\
\hline & a2 & 0.218 & $0.802 *$ & 0.262 \\
\hline & a3 & 0.316 & $0.768 *$ & 0.249 \\
\hline & $\mathrm{a} 4$ & 0.373 & $0.631 *$ & 0.291 \\
\hline & a5 & 0.381 & $0.611 *$ & 0.348 \\
\hline \multirow{7}{*}{ ETSM } & b1 & $0.725 *$ & 0.282 & 0.292 \\
\hline & b2 & $0.770 *$ & 0.173 & 0.279 \\
\hline & b3 & $0.754 *$ & 0.201 & 0.211 \\
\hline & b4 & $0.681 *$ & 0.342 & 0.196 \\
\hline & b5 & $0.666^{*}$ & 0.436 & 0.240 \\
\hline & b6 & $0.686 *$ & 0.360 & 0.247 \\
\hline & b7 & $0.648 *$ & 0.461 & 0.261 \\
\hline \multirow{4}{*}{ ETSE } & $\mathrm{c} 1$ & 0.374 & 0.264 & $0.703 *$ \\
\hline & c2 & 0.267 & 0.193 & $0.782 *$ \\
\hline & c3 & 0.163 & 0.243 & $0.815^{*}$ \\
\hline & c4 & 0.292 & 0.309 & $0.652 *$ \\
\hline Total Variance Ex & \multicolumn{4}{|c|}{$68.762 \%$} \\
\hline
\end{tabular}

Note: * indicates the internal consistency of each dimension in the questionnaire.

Extraction Method: Principal Component Analysis.

Rotation Method: Varimax with Kaiser Normalization. Rotation converged in 6 iterations.

\subsubsection{Confirmatory Factor Analysis}

After the exploratory factor analysis, this study conducted confirmatory factor analysis. The results can be seen in Figure 1 and some indicators have been listed in Table 5.

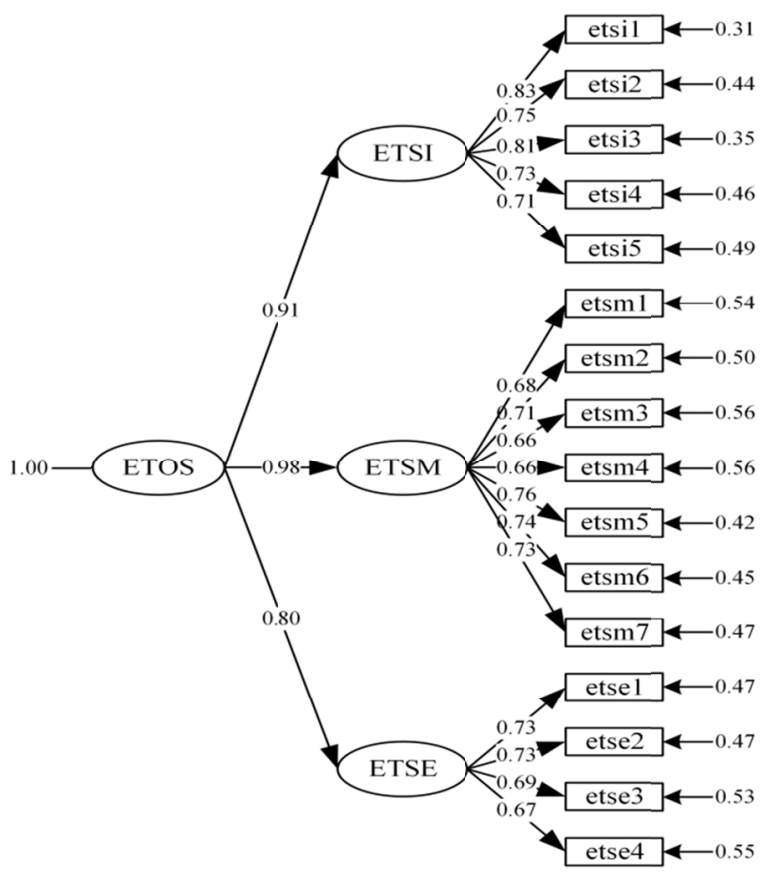

Chi-Square $=353.66, \mathrm{df}=101, \mathrm{P}$-value $=0.00000, \mathrm{RMSEA}=0.084$

Figure 1. Results of confirmatory factor analysis 
Table 5. Indicators of confirmatory factor analysis

\begin{tabular}{lllllllll}
\hline Indicators & $\chi^{2} / \mathrm{df}$ & GFI & AGFI & SRMR & RMSEA & NFI & CFI & IFI \\
\hline Value & 3.501 & 0.890 & 0.852 & 0.045 & 0.084 & 0.963 & 0.974 \\
Standard & $<5$ & $>0.8$ & $>0.8$ & $<0.08$ & $<0.1$ & $>0.974$ & $>0.9$ & $>0.9$ \\
\hline
\end{tabular}

All these indicators meet the criteria of confirmatory factor analysis and this means the scale has a good construct validity.

\subsection{Convergence validity}

According to Figure 1, all the standardization factors loads are greater than 0.5 and CR (composite reliability) and AVE (average variance extracted) can be easily calculated. The results can be seen in Table 6 .

Table 6 Results of CR and AVE

\begin{tabular}{|c|c|c|c|c|}
\hline Indicators & ETSI & ETSM & ETSE & Standard \\
\hline $\mathrm{CR}$ & 0.877 & 0.875 & 0.797 & $>0.7$ \\
\hline AVE & 0.590 & 0.500 & 0.496 & $>0.5$ \\
\hline
\end{tabular}

Compared the results of CR and AVE with the standard value, most results can be tested. Although the value of AVE of ESTE is lower than 0.5, this paper thinks it is still can be accepted considering that its value is very close to 0.5 .

\subsection{Discriminant validity}

Table 7. Inter correlations among three dimensions

\begin{tabular}{lccc}
\hline Coefficient & ETSI & ETSM & ETSE \\
\hline ETSI & 1.000 & & \\
ETSM & 0.883 & 1.000 & \\
ETSE & 0.727 & 0.784 & 1.000 \\
\hline
\end{tabular}

The P-value is 0.00000 (Figure 1).

According to Mcdonald and $\mathrm{Ho}(2002)$, the inter correlation coefficient between variables is less than 0.85 is acceptable. Most of coefficient meet the requirement, only the inter correlation coefficient between ETSI and ETSM is more than 0.85 . Considering the fact that, to some extent, ETSI and ETSM have something in common, most of the front-line employees cannot distinguish ESTI and ESTM completely and accurately, this paper thinks it is also can be accepted.

\section{Conclusion}

By analyzing employees' trust in organizational safety, the following conclusions can be drawn:

Firstly, employees' trust in organizational safety can be divided into three dimensions, including employees' trust in organizational safety institution, employees' trust in organizational safety management practices and employees' trust in organizational safety equipment, and this paper developed a 16-items scale.

Secondly, the good reliability and validity of the developed questionnaires shows the fact that organizations can easily strengthen employees' trust in organizational safety through efforts to improve these three aspects. Besides, these questionnaires can be used as a reliable measure for further research on employees' trust in organizational safety and its relationship with employees' actual behavior.

\section{Acknowledgements}

We are very grateful to National Natural Science Foundation of China under Grant $<71403108>$; National Natural Science Foundation of China under Grant $<71373104>$; China's Postdoctoral Science Fund $<2016$ M590426>; Postdoctoral science fund of Jiangsu Province $<1501073$ C $>$; humanities and Social Science of Ministry of Education fund $<19$ YJAZH059 $>$ for funding this research. 


\section{References}

Amponsah-Tawiah, K., \& Mensah, J. (2016). Occupational health \& safety and organizational commitment: evidence from ghanaian mining industry. Safety \& Health at Work, 7(3), 225-230. https://doi.org/10.1016/j.shaw.2016.01.002

Avram, E., Ionescu, D., \& Mincu, C. L. (2015). Perceived safety climate and organizational trust: the mediator role of job satisfaction. Procedia-Social and Behavioral Sciences, 187, 679-684. https://doi.org/10.1016/j.sbspro.2015.03.126

Burns, C., Mearns, K., \& Mcgeorge, P. (2006). Explicit and implicit trust within safety culture. Risk Analysis, 26(5), 1139-1150. https://doi.org/10.1111/j.1539-6924.2006.00821.X

Burt, C. D. B., Williams, S., \& Wallis, D. (2012). New recruit safety expectations: relationships with trust and perceived job risk. Safety Science, 50(4), 1079-1084. https://doi.org/10.1016/j.ssci.2011.11.019

Chathoth, P. K., Mak, B., Sim, J., Jauhari, V., \& Manaktola, K. (2011). Assessing dimensions of organizational trust across cultures: a comparative analysis of u.s. and indian full service hotels. International Journal of Hospitality Management, 30(2), 233-242. https://doi.org/10.1016/j.ijhm.2010.09.004

Conchie, S. M., \& Burns, C. (2008). Trust and risk communication in high-risk organizations: a test of principles from social risk research. Risk Analysis, 28(1), 141-149. https://doi.org/10.1111/j.1539-6924.2008.01006.x

Conchie, S. M., \& Donald, I. J. (2009). The moderating role of safety-specific trust on the relation between safety-specific leadership and safety citizenship behaviors. Journal of Occupational Health Psychology, 14(2), 137-147. https://doi.org/10.1037/a0014247

Conchie, S. M., Donald, I. J., \& Taylor, P. J. (2006). Trust: missing piece(s) in the safety puzzle. Risk Analysis, 26(5), 1097-1104. https://doi.org/10.1111/j.1539-6924.2006.00818.x

Jones, G. R., \& George, J. M. (1998). The experience and evolution of trust: implications for cooperation and teamwork. Academy of Management Review, 23(3), 531-546. https://doi.org/10.5465/amr.1998.926625

Kath, L. M., Magley, V. J., \& Marmet, M. (2010). The role of organizational trust in safety climate's influence on organizational outcomes. Accident Analysis \& Prevention, 42(5), 1488-1497. https://doi.org/10.1016/j.aap.2009.11.010

Kath, L. M., Marks, K. M., \& Ranney, J. (2010). Safety climate dimensions, leader-member exchange, and organizational support as predictors of upward safety communication in a sample of rail industry workers. Safety Science, 48(5), 643-650. https://doi.org/10.1016/j.ssci.2010.01.016

Lewicki, R. J., Mcallister, D. J., \& Bies, R. J. (1998). Trust and distrust: new relationships and realities. Academy of Management Review, 23(3), 438-458. https://doi.org/10.5465/amr.1998.926620

Lewis, J. D., \& Weigert, A. (1985). Trust as a social reality. Social Forces, 63(4), 967-985. https://doi.org/10.1093/sf/63.4.967

Luria, G. (2010). The social aspects of safety management: trust and safety climate. Accident Analysis \& Prevention, 42(4), 1288-1295. https://doi.org/10.1016/j.aap.2010.02.006

Mayer, R., Davis, J., \& Schoorman, D., (1995). An integrative model of organizational trust. The Academy of Management Review, 20(3), 709-734. https://doi.org/10.5465/amr.1995.9508080335

Mcdonald, R. P., \& Ho, M. H. (2002). Principles and practice in reporting structural equation analyses. Psychological Methods, 7(1), 64-82. https://doi.org/10.1037/1082-989X.7.1.64

Mullen, J., Kelloway, E. K., \& Teed, M.. (2017). Employer safety obligations, transformational leadership and their interactive effects on employee safety performance. Safety Science, 91, 405-412. https://doi.org/10.1016/j.ssci.2016.09.007

Neal, A., \& Griffin, M. A. (2006). A study of the lagged relationships among safety climate, safety motivation, safety behavior, and accidents at the individual and group levels. Journal of Applied Psychology, 91(4), 946-953. https://doi.org/10.1037/0021-9010.91.4.946

Ng, T. W. H. (2015). The incremental validity of organizational commitment, organizational trust, and organizational identification. Journal of Vocational Behavior, 88, 154-163. https://doi.org/10.1016/j.jvb.2015.03.003

Podsakoff, P. M., Mackenzie, S. B., Moorman, R. H., \& Fetter, R. (1990). Transformational leader behaviors and their effects on followers' trust in leader, satisfaction, and organizational citizenship behaviors. Leadership 
Quarterly, 1(2), 107-142. https://doi.org/10.1016/1048-9843(90)90009-7

Rämö, H. (2004). Moments of trust: Temporal and spatial factors of trust in organizations. Journal of Managerial Psychology, 19(8), 760-775. https://doi.org/10.1108/02683940410568248

Ranca, C. A., \& Iordănescu, E. (2013). Assessment of organizational trust: preliminary data for romanian adaptation of the organizational trust inventory short form. Procedia - Social and Behavioral Sciences, 78(2), 436-440. https://doi.org/10.1016/j.sbspro.2013.04.326

Rousseau, D. M., Sitkin, S. B., Burt, R. S., \& Camerer, C. (1998). Not so different after all: a cross-discipline view of trust. Academy of Management Review, 23(3), 393-404. https://doi.org/10.5465/amr.1998.926617

Shabnam, B., \& Parivash, J. (2012). The relationship between organizational justice and organizational trust. Procedia Social and Behavioral Sciences, 47, 1622-1626. https://doi.org/10.1016/j.sbspro.2012.06.873

Stoel, M. D., \& Muhanna, W. A. (2012). The dimensions and directionality of trust and their roles in the development of shared business-is understanding. Information \& Management, 49(5), 248-256. https://doi.org/10.1016/j.im.2012.06.001

Walker, A. (2010). The development and validation of a psychological contract of safety scale. Journal of Safety Research, 41, 315-321. https://doi.org/10.1016/j.jsr.2010.06.002

Whitener, E. M. (2001). Do "high commitment" human resource practices affect employee commitment?: a cross-level analysis using hierarchical linear modeling. Journal of Management, 27(5), 515-535. https://doi.org/10.1177/014920630102700502

Zhang, A. Y., Tsui, A. S., Song, L. J., Li, C., \& Jia, L. (2008). How do I trust thee? The employee-organization relationship, supervisory support, and middle manager trust in the organization. Human Resource Management, 47(1), 111-132. https://doi.org/10.1002/hrm.20200

\section{Copyrights}

Copyright for this article is retained by the author(s), with first publication rights granted to the journal.

This is an open-access article distributed under the terms and conditions of the Creative Commons Attribution license (http://creativecommons.org/licenses/by/4.0/). 